\title{
Comparative Anatomy of the Bands of Schreger*
}

\author{
By \\ Naobumi Kawai \\ (Department of Anatomy, Tokyo Medical and Dental University)
}

\section{Introduction}

In the previous paper (2) the author presented the study on the tooth structure of various kinds of Proboscidea with the conclusion that it is possible to identify both recent and fossile forms of the suborders of the Proboscidea by means of the microscopic structure of their teeth.

Since the most notable of all the microscopic structures of the enamel in the Proboscidea was found to be the bands of Schreger, the study on this was extended into almost all orders of the mammals. The results on this study indicate that the structure of the bands of Schreger is characteristic to each species with respect to the zonial component as well as the course of enamel rods, breadth, and combination of zoniae and so forth. It seems, therefore, not too presumptuous to state that the bands of Schreger constitute a species specific structure of the enamel on which may be based the classification of the mammals and the identification of their fossile forms.

None of a large number of reports published so far on the microscopic structure of the enamel deals with the comparative anatomy of the bands of Schreger. In all popular text-books of dental histology such as those of Mummery, Tomes, Meyer, Orban etc., the bands of Schreger are described in more or less details, but none of them presents their differences in different species.

\footnotetext{
* Dr. S. Iziri, former Director of the Geology Department of the Tokyo Science Museum, asigned me this problem and supported the work in every way. The investigation was then continued under the guidance of Dr. T. Fujita, Professor of Anatomy of Tokyo University. The invaluable guidance and support given by these gentlemen to the author's present study are gratefully acknowleded.
} 
However, there is one report on this problem, as far as the author is aware, which is that of Preiswerk. In 1894, he made a preliminary report on the comparative study of the Schreger's bands and noted the specific characteristics of the bands in the mammals. In the subsequent papers appeared in 1895 and 6, he presented the results of the studies of the teeth of the Equidae and the allied animals and the characteristic feature of the bands of Schreger for each of the families. These publications have not attracted much attention due seemingly to the fact that they were confined to the studies of the fossil Equidae and published only in preliminary forms.

\section{Material and Methods}

Our observation was made mostly on hematoxylinstained ground sections. Because of the capriciousness of the stain, it was not easy to obtain good preparations from all teeth. Some specimens in the following list are made of only one tooth each and in these it was not hopeful to obtain a perfectly stained section. In addition to the sectioning, the celluloid printing method for the ground surface was also adopted.

From the study of several sections of one tooth and of different teeth of the same species, it was found that the pattern of the bands of Schreger in the sections are not always the same in the same tooth or in different teeth belonging to the same species. It was, therefore, necessary to find the average structure from observations of a large number of preparations. This was difficult, however, when there was only a single tooth available. In such cases, the teeth were cut into as many sections as possible with a special disk and these were ground carefully.

Unless otherwise stated, the descriptions in the following sections are based on the structure of the longitudinal sections of the crown. The cross sections do not usually show the bands of Schreger.

The animals investigated are as follows:

1) Primates: Homo, Gorilla, Simia satyrus, Hylobates, Macacus fuscatus, Macacus cyclopis, Macaca cynomolga, Mycetes, Ateles, Hapale jacchus, Lemur, and Tarsius,

2) Chiroptera: Pteropus, Rhinolophus and Pipistrellus,

3) Insectivora : Mogera wogura,

4) Rodentia: Rattus rattus alexandrinus, Rattus norvegicus norvegicus, Rattus norvegicus hibernicus, Rattus norvegicus albus, Mus musculus, mus molossinus, Nutria, Petaurista leucogenys, Sciurus lis, Cavia cobaya, and Lepus cuniculus, 
5) Carnivora: Felis domestica, Felis tigris, Felis pardus, Canis familiaris, Nyctereutes procyonoides amurensis, Paguma larlotor, Ursus arctos lasiotus, Zalophus lobatus, and Phoca vitulina,

6) Cetacea: Physeter, Globicephalus, Delphinus delphis, Berardius, and Orca orcinus,

7) Ungulata: Sus scrofa domesticus, Giraffa camelopardalis, Bos taurus, Ovis aries, Capra hircus, Capreolus ochracea, Hydropotes arguropus, Capricornis crispus, Equus cavallus, Tapirus indicus, and Rhinoceros,

8) Proboscidea: Elephas indicus,

9) Sirenia: Halicore dugong,

10) Marsupialia: Cuscus, Macropus ruficollis, Macropus rufus, and Macropus dorsalis.

\section{Morphological analyses of the bands of Schreger}

For the sake of clear comparison and description, the bands of Schreger have been analysed according to the following features:

1) The course of the bands. In some animals such as the Squirrel, Flying squirrel, some Carnivores like the Cat, Bear etc. the dia- and parazoniae are practically straight, while in some others, such as the Primates, Ungulates, and some Carnivores, the course of the bands are more or less curved. Usually the course of the bands are parallel with that of the enamel rods of the parazoniae as in the Elefant, most Carnivores, Squirrel, etc., although this is not a necessary structure of the Schreger's figure. We shall return to this point shortly.

2) Attention should be paid to the disposition, whether the bands run through the entire layer of the enamel or there are indifferent zones'which show no zonial structure. To the former disposition belong most Carnivores with the Leopard (fig. 15) as its most typical example and some Ungulates as the Giraffe (fig. 22) and the Pig (fig. 21). In most of the Ruminants, however, the zonial figure occupies the middle part of the enamel, the deeper and the superficial layers showing a homogenous distribution of the enamel rods. A more accentuated condition of this kind is seen in that of the Equine (fig. 28). The rest of animals examined show the bands of Schreger originating immediately from the dento-enamel junction and disappearing in the superficial part of the enamel leaving here a more or less spacious indifferent zone.

3) The orientation of the bands in reference to the dento-enamel boundary is also an important character of the Schreger's figure. 
The angle between the dentin surface and the dia- or parazoniae is definitely specific to every species, although it is subject to individual and topographical variablility and the exact measurement of the angle is not always possible.

Generally speaking the bands are in every kind of animal ascending in their main course i.e. starting from the dento-enamel junction or deeper part of the enamel run obliquely towards the surface and incisad or cuspidad. The horizontal arrangement of the bands as seen in the Carnivores for instance is to be considered as the extreme case of the ascending courses. In some Carnivores in the cervical part of the crown the bands can be arranged even in a descending direction. However, if the middle and cuspidal parts of the crown are taken into consideration, the average orientation of the bands is always ascending. Again, in man the bands usually descend a little to bend upwards after a short course so that after all they give a general impression of ascending.

The following data being result of a rather rough survey of the middle part of the crown under microscope will nevertheless render an account of different orientations of the bands of Schreger in different animals.

1) Homo .......................... $80^{\circ} \pm$

Simia satyrus ................... $80-90^{\circ}$

Hylobates .......................... $80^{\circ} \pm$

Macacus fuscatus .............60-70

Macacus cyclopis ..............60-70

Macaca cynomolga ...........60-70

Hapale ............................. $80^{\circ} \pm$

Ateles $\ldots \ldots \ldots \ldots \ldots \ldots \ldots \ldots . . . . . . . . . . . . .70-80^{\circ}$

Lemur ............................. $80^{\circ} \pm$

2) Rattus norvegicus albus......45-80 $80^{\circ}$

Rattus alexandrinus ...........60-80 $80^{\circ}$

Mus mollossinus................45-60 $60^{\circ}$

Nutria (incisor) ..................6 $60^{\circ} \pm$

Cavia cobaya ...................50-70

Petaurista.......................... $90^{\circ} \pm$

Lepus cuniculus ................Incisors 50-80

Sciurus lis ...................... $90^{\circ} \pm$

3) Carnivora ......................... $90^{\circ} \pm$

4) Giraffa ..........................70-80 $80^{\circ}$

Bos taurus .......................4 $45^{\circ} \pm$ 
Ovis aries......................... $70^{\circ} \pm$

Hydropotes arguropus ........60-70 $70^{\circ}$

Capricornis ....................... $80^{\circ} \pm$

Sus scrofa domesticus .........70-80 $80^{\circ}$

Tapirus indicus ...............60-70

Equus cavallus ................45-60 $0^{\circ}$

5) Elephas .........................5 $50^{\circ} \pm$

Rhinocerus ......................4 $45^{\circ} \pm$

The above data clearly indicate the difference in the orientation of the Schreger's figure among different orders of the mammals. The differences among the families should, however, not be overlooked. Among the orders there are differences of various kinds, but within an order it is usually difficult to find a major difference in the pattern of the bands of Schreger.

4) The density of the bands i. e. their number found in $1 \mathrm{~mm}$ of the dento-enamel junction as well as the width of the diazoniae were calculated respectively measured. The figures in the table below were obtained through averaging several measurements or calculations.

5) Finally, the number of enamel rods contained in the width of the dia- and parazoniae is also essential for the characterization of the Schreger's figure. Although an exact survey is very difficult to carry out, the data in table 1 give a general view of the mentioned structure.

\section{Description of bands of Schreger in different kinds of mammals}

\section{1) Primates}

The pattern of the bands of Schreger in the. primate teeth is quite complicated. Description of the teeth of Gorilla should be omitted, because the sections prepared were not quite satisfactory. Description of the human teeth is also omitted, since there are enough reports about them.

In Orang-Utan, Macacus fuscatus, and Macacus cyclopis, which represent the catarrhine apes in our material, the zonial structure was almost the same with that of the human teeth. The diazoniae or dark bands originate closely from the dento-enamel junction, usually leaving a narrow space between them and the dentine which is filled with the bright enamel. The bands do not stand vertical to the dento-enamel junction, but make an angle of $60-70^{\circ}$ with it. They run rarely a straight course, usually slightly bending cuspidad in their peripheral half. 
Table 1.

Dimensions and numbers of the bands of Schreger.

In each column figures in parenthesis denote the average value.

\begin{tabular}{|c|c|c|c|c|}
\hline Name of animals & $\begin{array}{l}\text { Width of } \\
\text { diazone }\end{array}$ & $\begin{array}{c}\text { Number of } \\
\text { diazones in } \\
\text { dento-enamel } \\
\text { junction }\end{array}$ & $\begin{array}{l}\text { Number of } \\
\text { prisms in } \\
\text { one diazone }\end{array}$ & $\begin{array}{l}\text { Number of } \\
\text { prisms in } \\
\text { one parazone }\end{array}$ \\
\hline Homo & $\begin{array}{c}40-80 \\
(60)\end{array}$ & $\frac{7-14}{(9)}$ & $\begin{array}{l}8-15 \\
(9)\end{array}$ & $\begin{array}{l}7-15 \\
(10)\end{array}$ \\
\hline Simia satyrus & $\begin{array}{c}20-140 \\
(90)\end{array}$ & $\begin{array}{l}8-10 \\
(10)\end{array}$ & $\begin{array}{l}8-17 \\
(12)\end{array}$ & $\frac{8-10}{(9)}$ \\
\hline Hylobates & $\begin{array}{c}20-50 \\
(40)\end{array}$ & $\frac{9-10}{(9)}$ & $\begin{array}{c}5-11 \\
(9)\end{array}$ & $\begin{array}{l}7-13 \\
(8)\end{array}$ \\
\hline Macacus fuscatus & $\begin{array}{c}40-80 \\
(60)\end{array}$ & $\frac{6-13}{(9)}$ & $\frac{5-14}{(8)}$ & $\begin{array}{l}7-13 \\
(10)\end{array}$ \\
\hline Macacus cyclopis & $\begin{array}{c}40-80 \\
(60)\end{array}$ & $\frac{6-13}{(9)}$ & $\begin{array}{l}8-13 \\
(10)\end{array}$ & $\begin{array}{l}9-15 \\
(12)\end{array}$ \\
\hline Macaca cynomolga & $\begin{array}{c}40-80 \\
(70)\end{array}$ & $\begin{array}{c}6-14 \\
(9)\end{array}$ & $\begin{array}{l}5-12 \\
(9)\end{array}$ & $\frac{7-11}{(9)}$ \\
\hline Ateles & $\begin{array}{c}40-70 \\
(50)\end{array}$ & $\begin{array}{c}8-9 \\
(9)\end{array}$ & $\frac{5-12}{(9)}$ & $\begin{array}{c}8-11 \\
(9)\end{array}$ \\
\hline Hapale & $\begin{array}{c}20-40 \\
(35)\end{array}$ & $\begin{array}{c}11-13 \\
(11)\end{array}$ & $\begin{array}{c}5-9 \\
(6)\end{array}$ & $\begin{array}{c}6-13 \\
(9)\end{array}$ \\
\hline Lemur & $\begin{array}{c}20-30 \\
(25)\end{array}$ & $\begin{array}{c}16-20 \\
(18)\end{array}$ & $\begin{array}{c}3-7 \\
(4)\end{array}$ & $\begin{array}{c}4-7 \\
(5)\end{array}$ \\
\hline Lepus cuniculus & $\begin{array}{c}10-30 \\
(20)\end{array}$ & $\begin{array}{c}19-23 \\
(21)\end{array}$ & $\begin{array}{c}3-9 \\
(6)\end{array}$ & $\begin{array}{c}3-8 \\
(6)\end{array}$ \\
\hline Rattus alex. & & $\begin{array}{c}100-120 \\
(110)\end{array}$ & 1 & 1 \\
\hline Rattus norvegicus & & $\begin{array}{c}90-140 \\
(110)\end{array}$ & 1 & 1 \\
\hline Rattus norv. albus & & $\begin{array}{c}100-120 \\
(110)\end{array}$ & 1 & 1 \\
\hline Mus musculus & & $\begin{array}{c}100-150 \\
(130)\end{array}$ & 1 & 1 \\
\hline Nutria & $\begin{array}{c}15-40 \\
(20)\end{array}$ & $\begin{array}{c}16-19 \\
(17)\end{array}$ & $\begin{array}{c}4-6 \\
(5)\end{array}$ & $\begin{array}{c}6-9 \\
(7)\end{array}$ \\
\hline Petaurista leucogenys & & $\begin{array}{c}70-90 \\
(80)\end{array}$ & 1 & 1 \\
\hline Sciurus lis & & $\begin{array}{c}100-110 \\
(100)\end{array}$ & 1 & 1 \\
\hline
\end{tabular}




\begin{tabular}{|c|c|c|c|c|}
\hline Cavia cobaya & $\begin{array}{c}15-30 \\
(20)\end{array}$ & $\begin{array}{c}19-28 \\
(23)\end{array}$ & $\begin{array}{c}3-5 \\
(4)\end{array}$ & $\begin{array}{c}5-8 \\
(7)\end{array}$ \\
\hline Felis domestica & $\begin{array}{c}40-80 \\
(60)\end{array}$ & $\begin{array}{l}8-16 \\
(11)\end{array}$ & $\begin{array}{c}6-12 \\
(8)\end{array}$ & $\begin{array}{c}5-8 \\
(7)\end{array}$ \\
\hline Felis tigris & $\begin{array}{c}40-60 \\
(50)\end{array}$ & $\begin{array}{l}9-11 \\
(10)\end{array}$ & $\frac{7-11}{(9)}$ & $\begin{array}{l}6-13 \\
(10)\end{array}$ \\
\hline Felis pardus & $\begin{array}{c}4.0-80 \\
(60)\end{array}$ & $\begin{array}{l}9-11 \\
(10)\end{array}$ & $\begin{array}{c}6-10 \\
(9)\end{array}$ & $\frac{6-11}{(9)}$ \\
\hline Canis familiaris & $\begin{array}{c}40-80 \\
(60)\end{array}$ & $\begin{array}{l}9-16 \\
(12)\end{array}$ & $\begin{array}{l}7-16 \\
(10)\end{array}$ & $\begin{array}{l}8-13 \\
(11)\end{array}$ \\
\hline Nyctereutes procyon. & $\begin{array}{c}30-50 \\
(40)\end{array}$ & $\begin{array}{c}11-14 \\
(12)\end{array}$ & $\frac{4-10}{(7)}$ & $\begin{array}{c}6-8 \\
(6)\end{array}$ \\
\hline Paguma larvata & $\begin{array}{c}30-40 \\
(30)\end{array}$ & $\begin{array}{l}9-12 \\
(11)\end{array}$ & $\begin{array}{c}4-11 \\
(6)\end{array}$ & $\begin{array}{l}6-111 \\
(10)\end{array}$ \\
\hline Ursus arctos & $\begin{array}{c}4.0-80 \\
(70)\end{array}$ & $\begin{array}{l}8-14 \\
(11)\end{array}$ & $\frac{6-14}{(9)}$ & $\begin{array}{l}9-16 \\
(10)\end{array}$ \\
\hline Phoca vitulina & $\begin{array}{c}30-40 \\
(35)\end{array}$ & $\begin{array}{c}10-16 \\
(12)\end{array}$ & $\frac{6-13}{(8)}$ & $\begin{array}{c}7-11 \\
(9)\end{array}$ \\
\hline Sus scrofa domest. & $\begin{array}{c}40-160 \\
(90)\end{array}$ & $\frac{6-12}{(9)}$ & $\begin{array}{c}12-16 \\
(15)\end{array}$ & $\begin{array}{l}8-20 \\
(14)\end{array}$ \\
\hline Giraffa & $\begin{array}{c}40-160 \\
(100)\end{array}$ & $\begin{array}{c}7-10 \\
(9)\end{array}$ & $\begin{array}{c}10-15 \\
(13)\end{array}$ & $\begin{array}{l}9-17 \\
(11)\end{array}$ \\
\hline Bos taurus & $\begin{array}{c}70-240 \\
(130)\end{array}$ & $\begin{array}{c}5-9 \\
(7)\end{array}$ & $\frac{12-18}{(14)}$ & $\begin{array}{c}10-15 \\
(13)\end{array}$ \\
\hline Ovis aries & $\begin{array}{c}40-60 \\
(50)\end{array}$ & $\begin{array}{l}7-14 \\
(10)\end{array}$ & $\begin{array}{l}7-14 \\
(10)\end{array}$ & $\begin{array}{l}9-15 \\
(11)\end{array}$ \\
\hline Hydropotes arguropus & $\begin{array}{c}4.0-80 \\
(60)\end{array}$ & $\begin{array}{l}9-12 \\
(10)\end{array}$ & $\begin{array}{l}8-14 \\
(10)\end{array}$ & $\begin{array}{c}7-8 \\
(7)\end{array}$ \\
\hline Capricornis crispus & $\begin{array}{c}40-60 \\
(50)\end{array}$ & $\begin{array}{c}6-11 \\
(9)\end{array}$ & $\begin{array}{c}7-9 \\
(8)\end{array}$ & $\begin{array}{c}10-15 \\
(12)\end{array}$ \\
\hline Equus & $\begin{array}{c}60-110 \\
(70)\end{array}$ & $\begin{array}{c}6-9 \\
(7)\end{array}$ & $\begin{array}{l}8-15 \\
(12)\end{array}$ & $\begin{array}{l}9-14 \\
(13)\end{array}$ \\
\hline Tapirus indicus & $\begin{array}{c}70-160 \\
(110)\end{array}$ & $\begin{array}{c}5-9 \\
(7)\end{array}$ & $\begin{array}{l}6-16 \\
(10)\end{array}$ & $\frac{7-10}{(8)}$ \\
\hline Rhinocerus & $\begin{array}{c}14.0-24.0 \\
(180)\end{array}$ & $\begin{array}{c}2-3 \\
(3)\end{array}$ & $\begin{array}{c}25-41 \\
(33)\end{array}$ & $\begin{array}{c}38-58 \\
(50)\end{array}$ \\
\hline Elephas indicus & $\begin{array}{c}70-180 \\
(120)\end{array}$ & $\begin{array}{c}5-7 \\
(6)\end{array}$ & $\begin{array}{c}11-26 \\
(16)\end{array}$ & $\begin{array}{l}9-37 \\
(20)\end{array}$ \\
\hline
\end{tabular}


Some of them may be bi- or trifurcated. Approximately in outer third (sometimes half or fourth) of the enamel the dark bands become faint and finally disappear so that the peripheral good part of enamel consists of bright rods and gives appearance of continuation of the parazoniae.

A conspicuous figure of the zonial structure in the catarrhine apes including man is that even the parazoniae are composed of more or less wavy rods, the main orientation of which crossing that of the bands of Schreger. In other words, there can be seen no rods passing parallel with each other and with the parazoniae itself. Tracing the rods in parazoniae we get an impression as if they run into the dark rods of the diazoniae. (Whether the both kinds of rods are really continuous or not is still a problem difficult to be solved).

The bands are relatively broad $(40-80 \mu)$, each of which consists of $5-15$ rods in its width. The number of bands attached to $1 \mathrm{~mm}$ dentoenamel junction was 6-14.

The arrangement of enamel rods in the Hylobates, which is one of the anthropoid apes, is surprisingly somewhat different from the standard pattern of the catarrhine apes. The diazoniae are narrower with a width of only $20-50 \mu$ consisting of $5-11$ rods. The parazoniae are relatively wide. The slender diazoniae are irregularly curved with occasional bifurcation. In the fissure regions of the crown is usually found no band of Schreger. The entire structure is somewhat similar to that of the platyrrhine apes.

The arrangement of rods in the platyrrhine apes is generally speaking rather simple. Among the specimens investigated Hapale (Marmoset) was the genus which showed best development of the zonial structure. Even here, however, the pattern of the bands of Schreger shows a considerable deviation from that of the catarrhine monkeys. The diazoniae, which are narrower than those in macaques and man, are separated from each other by thin bands of parazoniae. This feature is characterized by the fact that the diazoniae reach almost the enamel surface taking a straight course and the parazoniae are composed of enamel rods oriented mostly in the direction of their course. In short, the pattern of the bands of Schreger in Hapale resembles to that Carnivores as will be described later.

The enamel of Ateles, the Spider monkey, presents only a scanty zonial structure or none at all in some instances. In Mycestes, the Howling monkey, the enamel rods all run parallel to each other.

In Lemur also which is a representative of the Prosimiae the zonial structure is obscure. The diazoniae, which are not clearly bounded 
against the parazoniae, are short and narrow so that 16-20 of them are found in $1 \mathrm{~mm}$ of the enamel (7-9 in man and macaques). In the cuspidal or incisal part of the enamel, the diazoniae sometimes penetrate the enamel up to two thirds of it.

The enamel of Tarsius, another representative of the Prosimiae, has rods all running parallel to each other, without displaying any figure of Schreger.

2) Chiroptera: The representatives of this order studied, Pteropus, Pipistrellus and Miniopterus, were all devoid of any figure of Schreger in the enamel. The rods run simply straight and parallel except in cuspidal and fissural regions of molar teeth where the course of the rods is a little more complicated without forming any zonial arrangement.

3) Insectivora: In the teeth of the Mole every enamel rod takes a straight course and there is no bands of Schreger present.

4) Rodentia: The course of the enamel rods in the Rodents was carefully studied by $\mathrm{J}$. Tomes already in the middle of the last century. As regards the bands of Schreger, however, his observations do not seem to be quite complete and not without errors.

a) The pattern of Schreger of the Muridae is almost alike in three representatives (Rattus rattus, Rattus norvegicus, Mus musculus) studied. Its anatomical characteristics are so outstanding that their teeth can be recognized at a glance.

In sections, each of the dia- and parazoniae consists as a rule of a single layer of the rods. Since the cross section of the rods is quadrangular or rhomboid, the so-called diazoniae or dark zones appear like twisted ropes according to Fujita (fig. 6). The parazoniae which may be called the bright zones consist of rods which are thicker than those of the dark zones and with less affinity for stains. These rods are also arranged in such a way that in their cross or oblique sections the bright zones also look like twisted ropes.

The ropes of the rods, in both zones, may be sometimes divided into two ropes as demonstrated in fig. 6 . The boundary between the bright and dark zones is sharp and the two zones are also distinct in the color of the stain. There is, therefore no possible continuation of a rod from one zone to the next.

The zones run almost straight and parallel to each other. They start just from the dento-enamel junction to terminate a thin layer before the enamel surface. This layer where the zonial structure is absent, consists of rods which are of the same physical characteristics as those 
of the bright rods.

The oblique course of the bands in reference to the dento-enamel junction should be emphasized as one of the striking characteristics of the Muridae. The bands leave the dentine surface with an angle of $45-80^{\circ}$ and ascend obliquely towards the surface of the enamel.

The characteristic structure described above which can be seen in the incisor enamel is usually subject to some modification in the molars. The alternating dark and bright ropes are present only in the enamel near the neck. In the upper part of the crown i. e. in the enamel covering the cusps which is thicker than the cervical one, all rods show a parallel course without displaying the figure of Schreger.

b) The band pattern of the enamel of the Petaurista (Flying squirrel) (fig. 7) is very similar to that of the Rat with an alternating arrangement of bright and dark bands both consisting of a single row of cross sections of the prism. However, the bands look thicker and shorter than those of the Muridae, an appearance caused by the thinner layer of the Petaurista.

A definite distinction between the Flying squirrel and the Muridae is that the bands of the former are arranged exactly vertical to the borderline of the enamel, giving an appearance of a palisade. They disappear suddenly with an abrupt end underneath the enamel surface leaving here a rather broad zone of bright, indifferent enamel.

In the molar teeth the pattern of the bands of Schreger is quite different from that of the incisors. The most striking character of the molar enamel is the poor development of the zonial figure. The bands of Schreger are very indistinct and both dia- and parazoniae are composed of not one but of 5-8 enamel rods in the transverse direction and their number is about 20 in width.

c) The Sciuridae which stands very close in taxonomy to the Petauridae shows in the structure of the enamel a quite close relation with the Flying squirrel. Inspite of a careful observation we could hardly find any marks in the structure of the Schreger's figure which distinguish these two families from each other (compare fig. 7 with 8). One point should, however, be emphacised. The bands of Schreger in the Sciuridae are slightly thinner than those of the Petaurista (table 1). But we are not quite sure whether this difference holds with all kinds of Petauridae and Sciuridae.

d) The Nutria or Coypu is provided with a zonial structure which is unique to this family of the Rodent. In the incisors the bands of Schreger are very distinct, broad as compared with those of the 
Muridae consisting of 4-9 rods in their width, and run practically straight covering the entire ground surface of the enamel. The angle between the bands and the dentinal border of the enamel changes with the level of the teeth. In the incisal part it measures some $40^{\circ}$ while in the radicular part, $60 \sim 70^{\circ}$.

In the molars the pattern of the bands of Schreger is highly different from that of the incisors. Further, the indistinct outline of the bands is striking. The zonial figure is especially obscure in the middle layer of enamel and it is sometimes entirely absent giving an appearance of the indifferent zone. The bands are broader than those of the incisors and irregular in shape.

e) The zonial picture of the Caviidae is again very peculiar in its own way. In the incisors of the Guinea pig (fig. 11), each zone consists of a number (usually 3-6) of rods in the transverse direction. The arrangement of the rods within each band is irregular so that the bands in longitudinal section of their rods give a bushes appearance. The boundary of the bands is therefore not distinct and it seems that the rods of a band pass into an adjacent band of different orientation. Again, because of the irregular and curved course of the rods, we never encounter bands, where the rods are running parallel with each other. Some of the bright bands may be in their deeper portion divided by intercalation of an accessory dark band.

The bands are straight and run parallel with each other. The diazoniae sometimes disappear leaving a rather wide indifferent, bright zone, but sometimes and even in the same preparation they reach the very surface of the enamel.

In the molar teeth of the Guinea pig a zonial structure is absent. The enamel shows a parallel structure of the rods only in the deepest and the most superficial layer. In the middle layer, bundles of rods run twisted with each other and give a flame-like irregular appearance of the rods to the ground surface of the enamel.

f) Leporidae. The zonial pattern of the Hare and Rabbit is quite different from that of other rodent families described above. Its most striking feature is that the diazoniae and parazoniae blend with each other and lack a clear outline. The zones are rather broad relatively to their length. Furthermore, most of them do not run straight so that the whole area of zonial structure looks like a raging flame or a layer of clouds (fig. 12).

In the incisor the entire enamel layer is occupied by the zonial structure. The enamel rods do not run straight even in the so called 
parazoniae so that in any section they never appear in their longitudinal course.

In the Leporidae the arrangement of the rods in the molar teeth is modified from that of the incisors (fig. 13). The molar enamel is practically divided into two structurally different layers. The superficial layer which occupies a good half or a little more of the enamel displays the zonial structure characteristic of the leporoid teeth. The diazoniae are present in shape of spots or bands intensely stained with hematoxylin. The parazoniae are bright and make good contrast against the diazoniae. As the latter reach the surface of the enamel and the former are stained more deeply towards the surface. The distinction of the dia- and parazoniae is quite obscure in the most superficial small portion of the layer. The deeper half of the enamel, on the contrary, is clear of any zonial structure and all the rods run straight and parallel from the dentoenamel junction obliquely outwards and cuspidad.

In addition, it should be noted that some parts of the molar enamel, for instance, the thin layer intercalated between the dentinal foldings, contain only faint zonial figures similar to those of the incisors or they may not even show these figures.

5) Carnivora. The bands of Schreger are well developed in this order. The characteristic feature of the zonial pattern of the Carnivores may be summarized as follows: a) The dia- and parazoniae stand in most cases vertical to the dento-enamel junction and show a practically straight course. b) The diazoniae reach almost the surface of the enamel. c) Enamel rods in the parazoniae are arranged parallel to each other as well as to the course of the bands so that the boundary between the para- and diazoniae is rather clear (see for example fig. 15). d) The division of the diazoniae into two or three equal or unequal portions is less frequent than in the Primates and Ungulates.

The pattern of the Canidae (Canis familiaris) is very similar to that of the Felidae (Felis domestica, Felis pardus, Felis leo). It is almost impossible to postulate any specific feature to differentiate these families from each other. The density of the bands of Schreger makes no difference between the canine and feline enamel. The zonial pattern of the Bear is also very much like that of the feline and especially the canine teeth. Even the enamel of the Paguma, Procyon (Racoon), and Phoca scarcely displays in the Schreger's structure any deviation from the characteristic feature of the Carnivores. In the Paguma, especially in its front teeth, it is almost impossible to formulate any difference in the Schreger's feature from that of the Cat or the Dog. The bands 
of Schreger of the Racoon are rather irregularly arranged. In the pinnipedian teeth (Zalophus lobatus and Phoca) the diazoniae are not sharply bordered upon the surrounding parazoniae so that the pattern is intermediate between the Primates and the Carnivores.

Within each family of the Carnivora, the differentiation of one genus from another was in most cases impossible. Only in the feline family, the zonial feature of the Leopard is distinguished easily from the Cat and the Tiger. The diazoniae or dark bands of the Leopard are not only sharply bordered against the diazoniae but reach the very surface of the enamel (fig. 15).

6) Cetacea. The teeth of the Odontoceti are as a rule coated with a thin layer of enamel in which the rods are rather evenly arranged without any trace of zonial structure.

7) Ungulata. The enamel of the Ungulates is provided with well developed bands of Schreger. The diazoniae are very long in accordance with the thick enamel. They start close to or with a interspace from the dento-enamel junction and pass obliquely upwards i.e. coronad or incisad, arriving very peripheral layer of the enamel. Here they are shaded off into the superficial brighter zone.

Another characteristic feature of the Ungulate enamel consists in that the diazoniae blend with the parazoniae without any sharp boundaries as seen in the teeth of the Carnivores. The parazoniae are made up with brighter rods. These are, however, cut obliquely or even transversely, a condition which is similar to that of the Primate teeth. The rods in the diazoniae are mostly arranged in wavy or curved rows which run transversely to the bands of Schreger (fig. 24). The diazoniae may be divided into subzoniae. Sometimes accessory lesser bands are intercalated between adjacent two ordinary diazoniae. The para-and diazoniae describe mostly rather straight, or in some instances slightly curved course. The width of the diazoniae is $40-160 \mu$, average being $100 \mu$ and in $1 \mathrm{~mm}$ of the dento enamel border line approximately 7-10 of the diazoniae are found.

The differentiation of suborders or families from each other through the zonial structure is difficult since there are little differences. But if we observe many good sections carefully, some characteristic features could be noticed. Among the Ruminants the bands of Schreger of the Ox, Sheep, and Serow are of similar type as distinct zonial structure is present only in the middle half or two thirds of the enamel, leaving rather spacious indifferent or bandless layer in the surface as well as along the dento enamel junction (fig. $23,25,27$ ). On the contrary, the 
incisors of the Giraffe, also a family of the Ruminants, show practically the same structure with those of the Pig, the Schreger's bands extending up to the dento-enamel junction. It is interesting that the molar enamel has a pretty broad indifferent layer along the dento-enamel junction. The dark bands which are thick are $120-160 \mu$ in their breadth. In the Tapir the dark bands are slender than in the Pig; otherwise there is no peculiarity between these two animals.

The bands of Schreger in the Horse are in their histologic ap. pearance very much alike to those in the Ruminants. They are found only in the middle third of the enamel layer, while the deeper and superficial thirds are occupied by the indifferent structure. It should be remarked that in the Equine tooth the enamel surface is more or less resorbed, so that the connection of the coronal cementum with the enamel may be secured. If the resorption occurs to a certain extent, the superficial indifferent layer of the enamel might disappear. Otherwise we could not find any point distinguishing the Equine zonial pattern from that of the Ruminants.

8) Proboscidea. Only enamel of the molars of the Indian Elephant was investigated. The enamel of the Elephant has a considerable thickness in spite of the physiological resorption from the side of the cementum. The rods run obliquely to the longitudinal direction of the tooth and ascend and run outwards from the dentin, in order to bend on the half way suddenly into a horizontal course. The superficial half of the enamel layer is stained more intensively as compared with the deeper half.

The bands of Schreger are pretty well developed and show their own characters. The diazoniae are usually long and narrow and start immediately on the surface of the dentine. They run sometimes parallel to each other but sometimes in different directions. In the outer dark layer of the enamel, the Schreger's figure is not distinct. The rods are arranged mostly in the same direction.

In addition, there are to be seen a lot of smaller diazoniae in shape of spindle, comma, triangle, square and so forth, which are usually located in the vicinity of the dentin. On account of different orientation of the bands as well as of the rods in them, their arrangement give an appearance of an irregular mosaic work.

The most striking feature of the zonial structure in the Elephant enamel is the sharp boundary of the dia- and parazoniae. The parazoniae are formed with the rods running straight and parallel to each other, while in the diazoniae the rods are orianted quite in a different direction. Therefore, there is practically no transition of the rods from 
a para- into the adjacent diazoniae and vice versa. So the bands look like the faults in geology.

In connection with the above description, it should be noted that the teeth of the Rhinoceros stnw a very similar disposition of the bands of Schreger to that of the Elephant. Description is not given here, because only a single fossil section was available. We need more preparations especially of the recent species for a precise description.

9) Sirenia: The teeth of the Dugong have no bands of Schreger like those of the Cetacea.

10) Marsupialia. As representative of the Marsupialia, Cuscus (a kind of Phalanger) and Macropus were studied.

In the Cuscus the course of enamel rods is usually simple from the dento-enamel junction up to the surface of the crown. They all run practically straight and parallel to each other, so that they do not form any kind of bands of Schreger. However, the enamel covering the cusps and the masticatory surface of the molar teeth shows a wavy or inflected course of its rods. But, here we cannot yet speak of the bands of Schreger, because there is no alternation of dia- and parazoniae. Sometimes, in cusps covered with a thicker layer of enamel (500-700 $\mu$ ) there may be found a real figure of Schreger which contains a number of dia- and parazoniae. Each zonia is made up transversely with 3 or 4 enamel rods in the section. The only feature there is the rather superficial location of the bands in the enamel which never reach the dento-enamel junction as is the case in typical bands of Schreger.

\section{Summary}

This is a comparative anatomical study of the bands of Schreger in mammalian enamel. The observation was made on meridional ground section of the crown. The ground surface was stained with hematoxylin.

Through the investigation it was established that the mentioned structure of the enamel has a characteristic feature specific to each kind of animal. The pattern of the bands of Schreger can therefore be useful as one of the taxonomic criteria.

The zonial patterns can be classified into following main categories:

1) Carnivora type: The bands are conspicuous because the diazoniae consisting of cross sections of the enamel rods are bounded clearly against the parazoniae which are cut mostly in longitudinal direction and oriented parallel to the course of the bands. They stand vertical 
upon the dentine surface and describe rather a streight course. The indifferent bright layer under the enamel surface is relatively thin.

2) Primate type: The bands are relatively broad and each of them consists of 5-15 rods in its width. They stand oblique to the dentoenamel junction and run in more or less curved course. Leaving a thin indifferent layer above the dentine they vanish into a thicker bright layer under the enamel surface. The parazoniae are also composed with curved, oblique sections of the enamel rods so that the boundary of the dia-against the parazoniae is rather transitional.

3) Ungulate type: The bands are considerably long and the indifferent zones are broad in accordance with the thick enamel of the order. They stand oblique to the dento enamel junction and are more or less curved. The boundary between para- and diazoniae is still more obscure than that in the Primate type. Even in the parazoniae a parallel arrangement of the longitudinally cut rods is scarcely to encounter. The rods in the diazoniae are arranged in rows.

4) Rodent type: The para- and diazoniae are in most Rodents bounded sharply against each other and no transition of the rods from a band to the adjacent one can be seen. They are straight and consist of rather small number of enamel rods, mostly of a single row of them. The Leporidae and Caviidae have, however, their own patterns of the bands of Schreger. In general the molar teeth of the Rodents show zonial structures more or less modified from those found in the incisors.

\section{References}

1) Czerwinski, R., Vergleichendanatomisch-histologisshe Untersuchungen über den Bau der harten Zahnsubstanzen beim Macacus rhesus. Diss. Würzburg 1926. (Cited from Anat. Bericht.)

2) Iziri, S., \& Kawai, N., Microscopic structure of the teeth of the Proboscidea. Bull. Tokyo Sci. Museum, 23, 1948. (Japanese).

3) Mummery, J.H., The microscopic and general Anatomy of the teeth, p. 36-39. 2. ed. London, 1924.

4) Owen, R., Odontography. London, 1840-45.

5) Preiswerk, G., Vorläufige Mitteilungen über die Untersuchungen des Zahnschmelzes der Säugetiere. Anat. Anz., 9, 1894.

6) Do., Schmelzstructur und Phylogenie. Verh. d. Anat. Ges. 9. Vers. Basel, 1895.

7) Do., Schmelzstructur und Phylogenie (Nachtrag). Anat. Anz., 11, 1896.

8) Do., Einiges über die Schmelzstructur. D. Mschr. Zhk., 9, 1900.

9) Shobusawa, M., Vergleichende Untersuchungen über die Form der Schmelzprismen der Säugetiere. Okajimas Folia Anat. Jap., 24, 1952.

10) Taut, A., Histologische Untersuchungen über die Praemolaren und Molaren von Hippopotamus amphibius. Diss. Würzburg. 1932. (Cited from Anat. Bericht.) 
11) Tomes, Ch. S., A manual of dental anatomy, p. 43-46. 8. ed. London, 1923.

12) Tomes, J., On the structure of the dental tissues of the order Rodentia. Phil. Trans. Roy. Soc. London, p. 529-67, 1850.

\section{Explanation of Figures}

Fig. 1. Human incisor, $\times 50$.

Fig. 2. Orang Utan (Molar), $\times 60$.

Fig. 3. Macacus fuscatus (molar), $\times 65$.

Fig. 4. Hylobates (molar), $\times 180$.

Fig. 5. Hapale (premolar), $\times 135$.

Fig. 6. Rattus alexandrinus (incisor), $\times 345$.

Fig. 7. Petaurista (upper incisor), $\times 345$.

Fig. 8. Sciurus lis (incisor), $\times 345$.

Fig. 9. Nutria (incisor), $\times 130$.

Fig. 10. Nutria (molar), $\times 120$.

Fig. 11. Cavia cobaya (incisor), $\times 290$.

Fig. 12. Lepus cuniculus (incisor), $\times 290$.

Fig. 13. Lepus cuniculus (molar), $\times 180$.

Fig. 14. Felis domestica (incisor), $\times 155$.

Fig. 15. Felis pardus (molar), $\times 135$.

Fig. 16. Canis familiaris (molar), $\times 135$.

Fig. 17. Nyctereutes procyonoides (molar), $\times 135$.

Fig. 18. Paguma larvata taivana (incisor), $\times 135$.

Fig. 19. Ursus arctos lasiotus (canine). $\times 130$.

Fig. 20. Phoca vitulina (moiar), $\times 135$.

Fig. 21. Sus scrofa domesticus (molar), $\times 65$.

Fig. 22. Giraffa camelopardalis (molar), $\times 80$.

Fig. 23. Bos taurus (molar), $\times 65$.

Fig. 24. Bos taurus (incisor), $\times 365$.

Fig. 25. Ovis aries (molar), $\times 135$.

Fig. 26. Hydropotes arguropus (molar), $\times 90$.

Fig. 27. Capricornis crispus (molar), $\times 85$.

Fig. 28. Equus cavallus (molar), $\times 75$.

Fig. 29. Tapirus indicus (premolar), $\times 65$.

Fig. 30. Rhinoceros (molar), $\times 160$.

Fig. 31. Elephas indicus, (molar), $\times 50$. 
Plate I
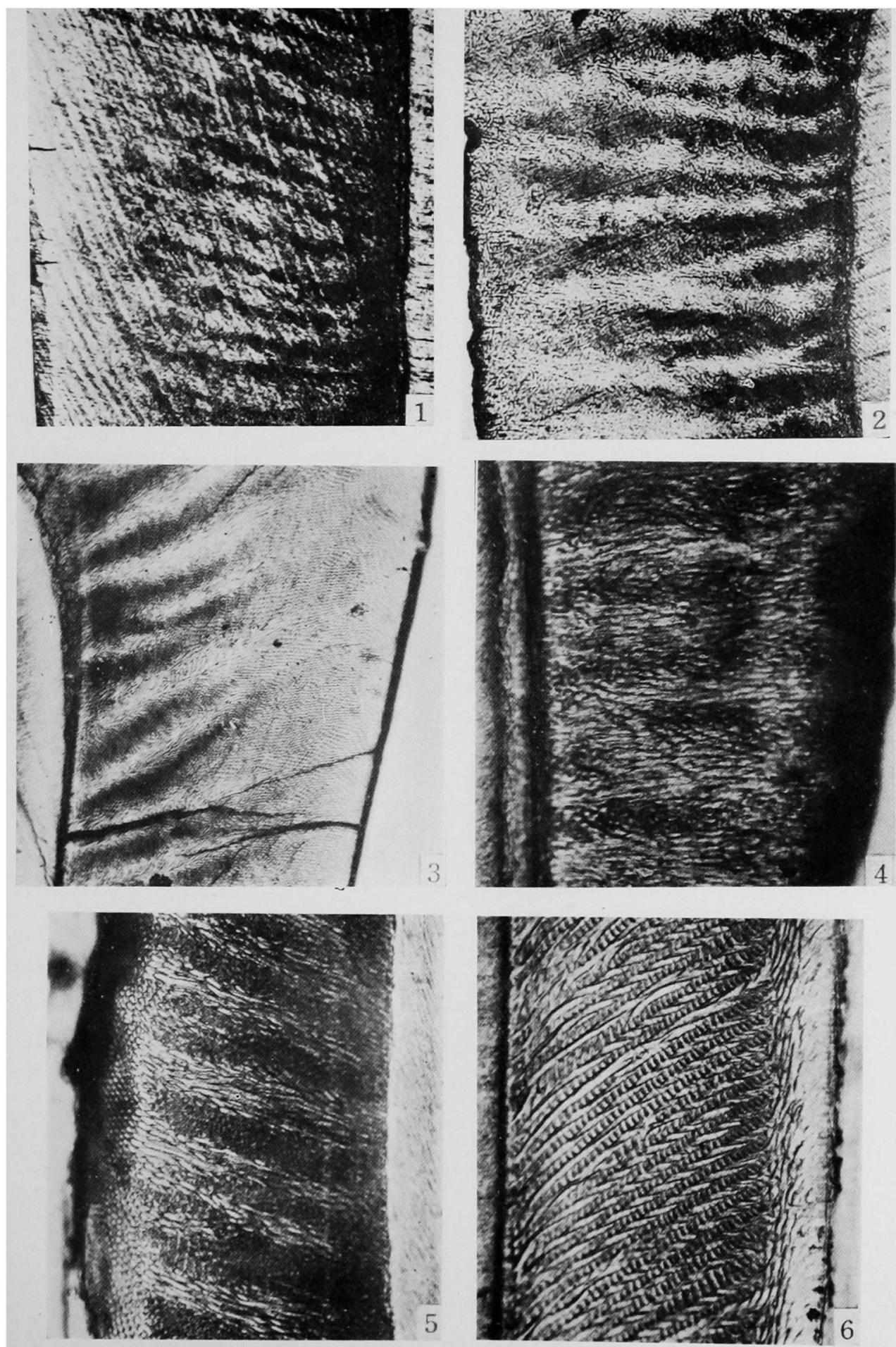

N. Kawai 
Plate II
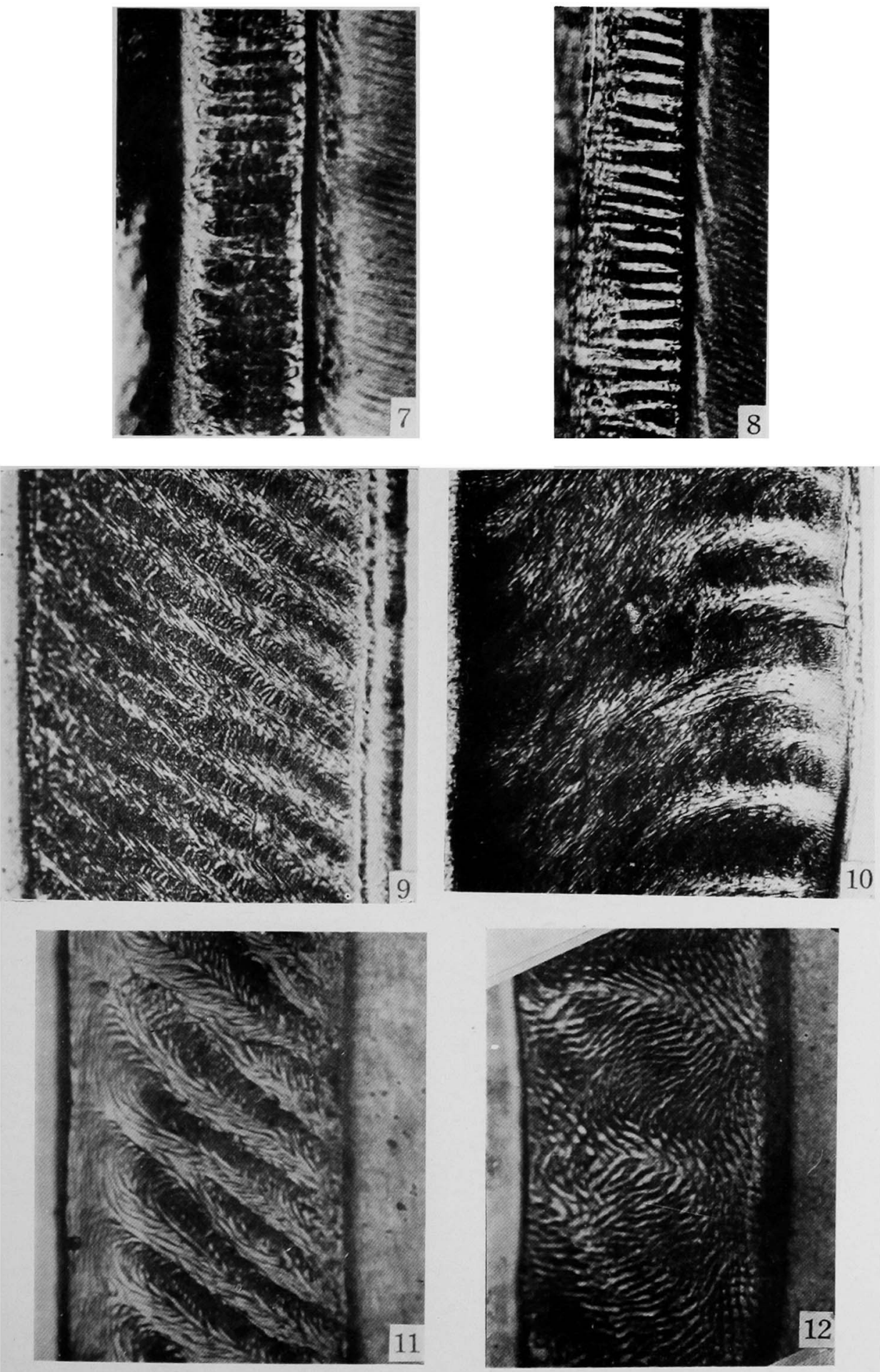

N. Kawai 
Plate III
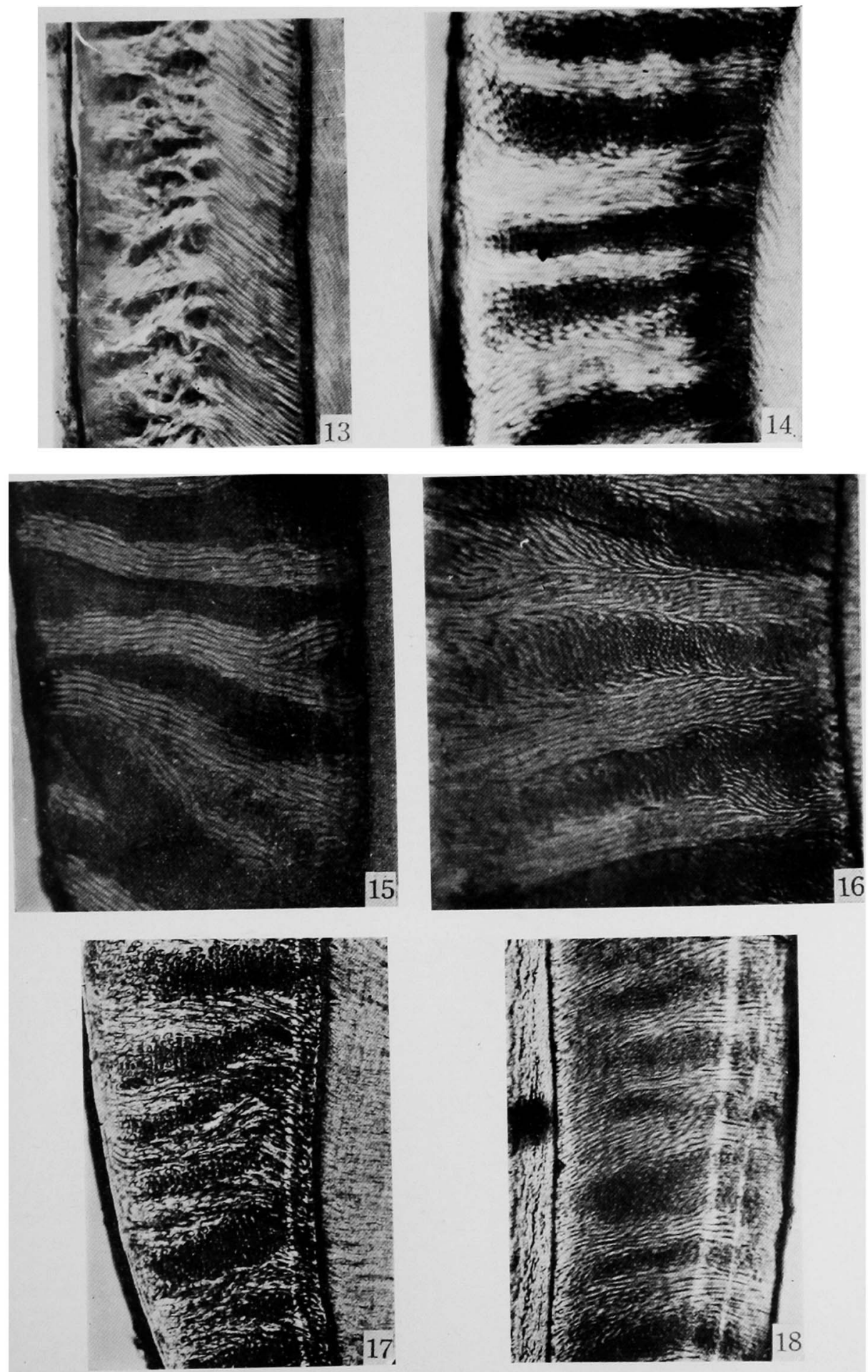

N. Kawai 
Plate IV
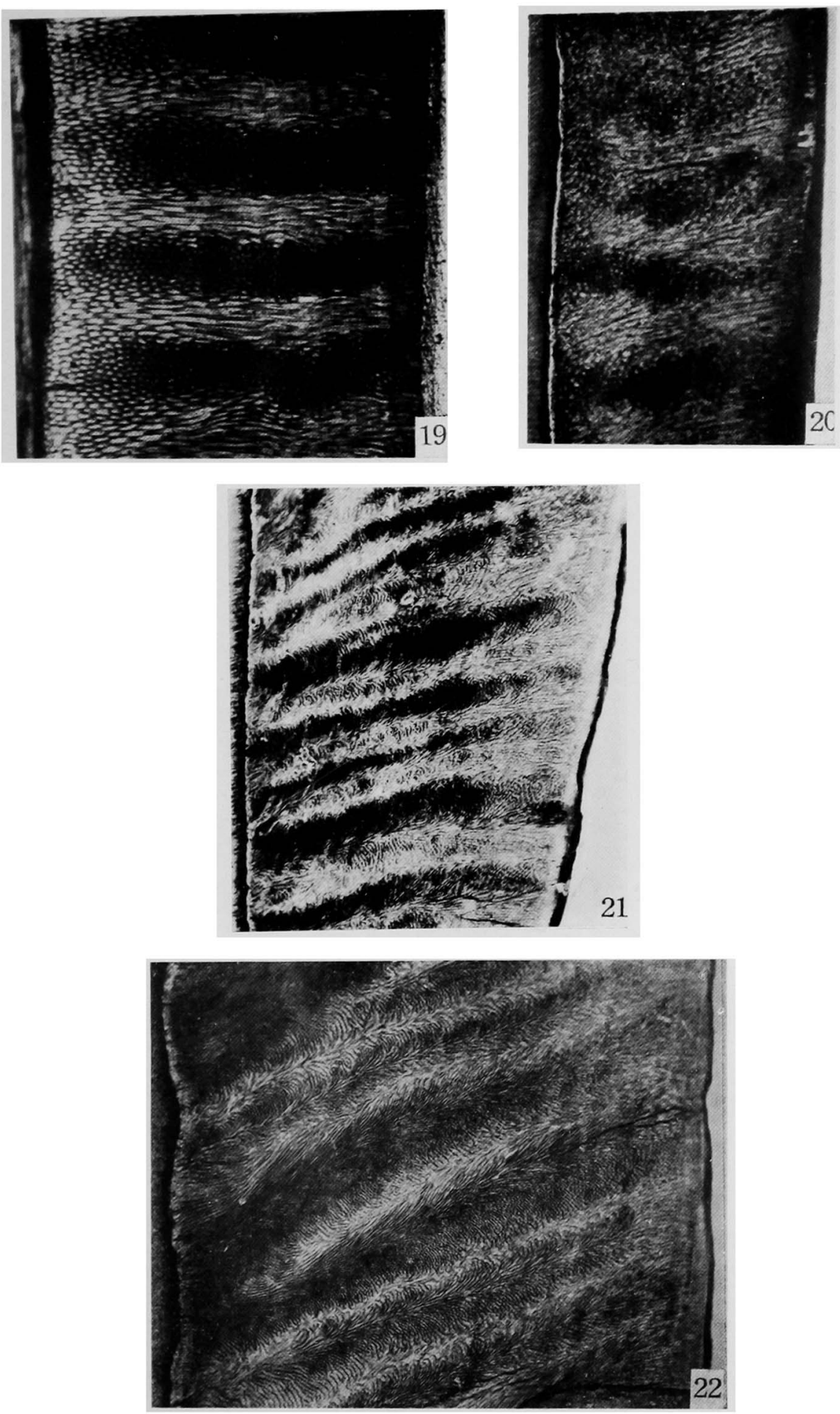

N. Kawai 
Plate V
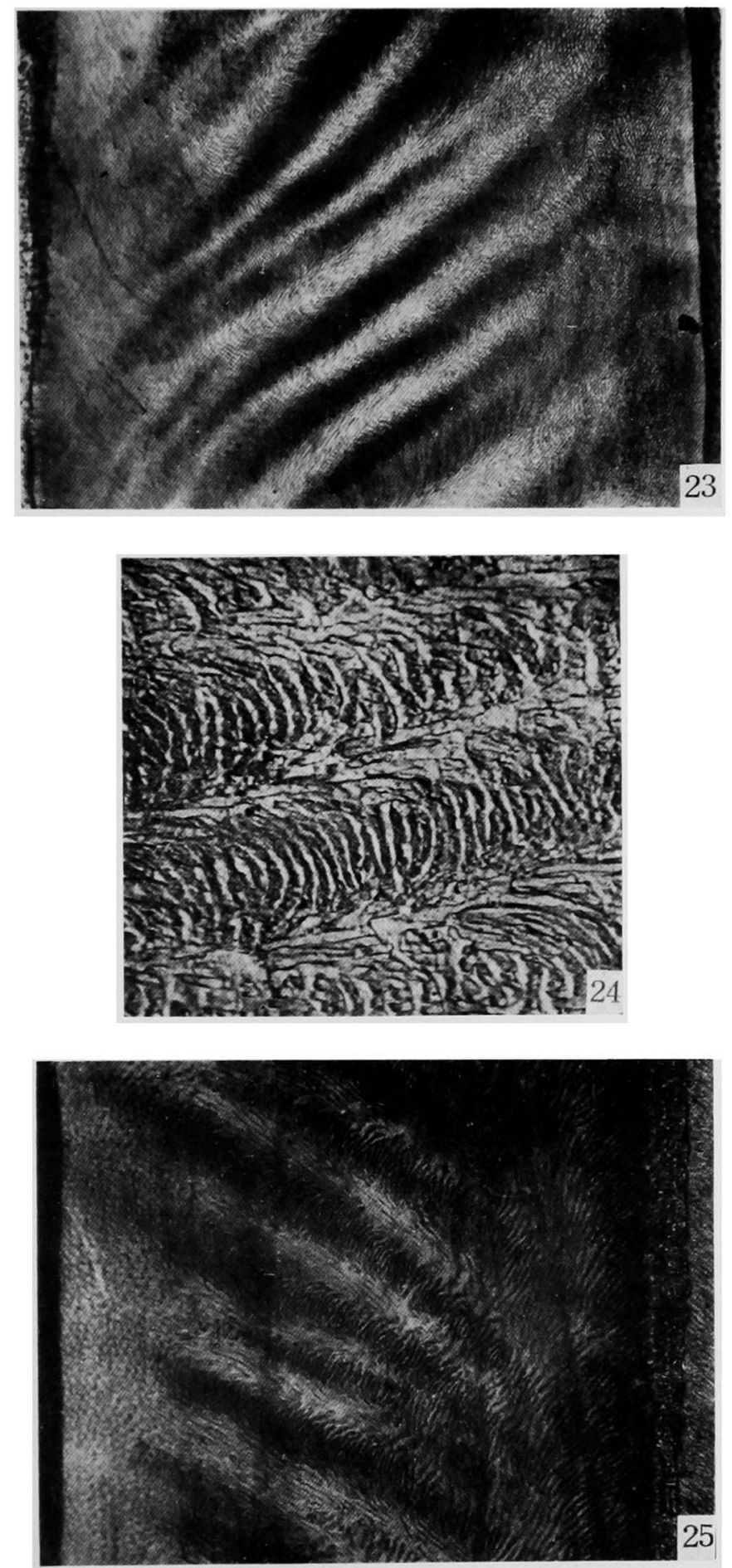

N. Kawai 
Plate VI
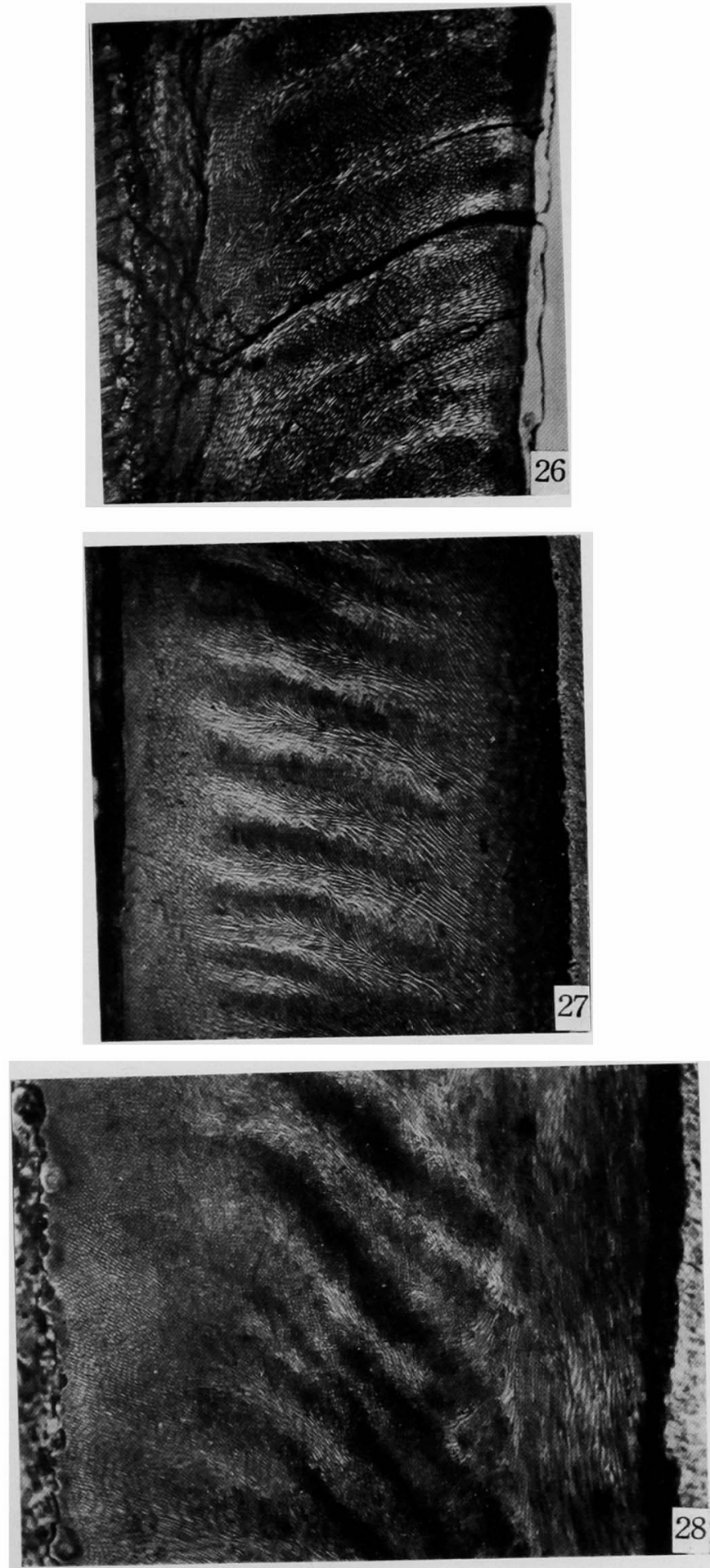

N. Kawai 
Plate VII
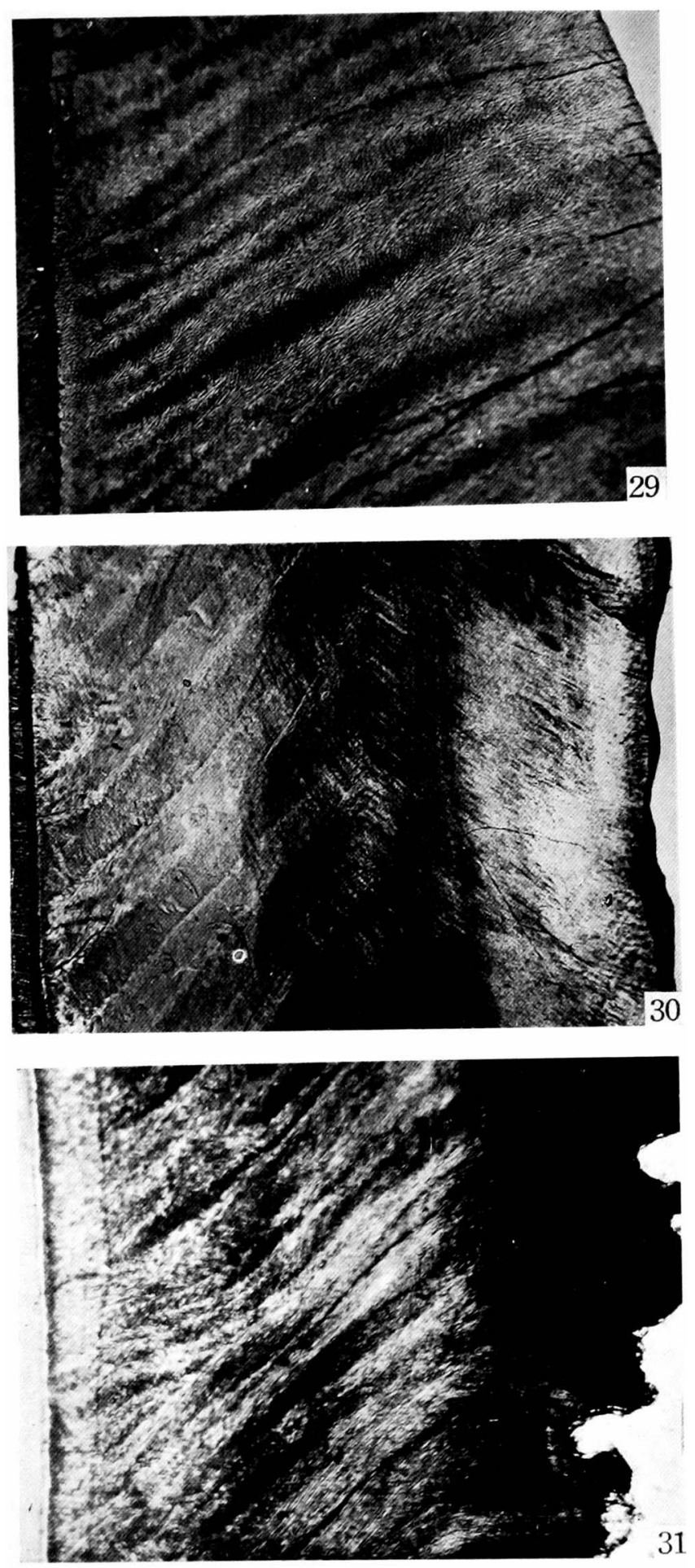

N. Kawai 